\title{
Oligodendrocyte cell death in pathogenesis of multiple sclerosis: Protection of oligodendrocytes from apoptosis by complement
}

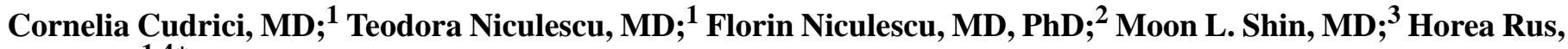 \\ MD, PhD $^{1,4 *}$ \\ Departments of ${ }^{1}$ Neurology, ${ }^{2}$ Medicine-Division of Rheumatology and Clinical Immunology, and ${ }^{3}$ Pathology, Univer- \\ sity of Maryland School of Medicine, Baltimore, MD; ${ }^{4}$ Department of Veterans Affairs (VA) Maryland Health Care \\ System, Multiple Sclerosis Center of Excellence East, Baltimore VA Medical Center, Baltimore, MD
}

\begin{abstract}
Multiple sclerosis (MS) is a chronic inflammatory demyelinating disease of the central nervous system. It is mediated by activated lymphocytes, macrophages, microglia, and complement. In MS, myelin-forming oligodendrocytes (OLGs) are the targets of inflammatory and immune attacks. OLG death by apoptosis or necrosis causes the cell loss seen in MS plaques. Studies of experimental allergic encephalomyelitis (EAE) in caspase 11-deficient mice show that caspasemediated death of OLGs is critical to demyelination. Complement activation may affect MS pathogenesis through activated terminal complex C5b-9, which promotes demyelination, and through sublytic C5b-9, which protects OLGs from apoptosis. By inducing EAE in C5-deficient mice, we showed that complement C5 promotes axon preservation and new myelin formation, which protect OLGs from apoptosis. These findings indicate that activated complement C5b-9 plays a proinflammatory role in acute MS but may also protect OLGs from death in chronic MS.
\end{abstract}

Key words: apoptosis, caspases, complement C5, complement complex C5b-9, experimental allergic encephalomyelitis, Fas ligand, oligodendrocyte, multiple sclerosis, phosphatidylinositol-3 kinase, T lymphocyte.

\section{INTRODUCTION}

Multiple sclerosis (MS) is a chronic inflammatory demyelinating disease of the central nervous system (CNS). Although the cause of MS remains unknown, the cell death and tissue damage seen in MS is generally accepted to be caused by activation of the immune system and subsequent inflammation [1]. The pathogenesis of MS consists of inflammatory and neurodegenerative phases [1]. Acute MS lesions are generally characterized by active demyelination and inflammatory cell infiltrates, including $\mathrm{T}$ cells, B cells, macrophages, and activated microglia. Axonal transection is present in acute inflammatory

\footnotetext{
Abbreviations: $\mathrm{Bad}=\mathrm{Bcl}-2$-associated death promoter, $\mathrm{Bak}=$ Bcl-2-antagonist/killer, Bax = Bcl-2-asociated $\mathrm{X}, \mathrm{BBB}=$ bloodbrain barrier, $\mathrm{Bcl}-2=\mathrm{B}$ cell chronic lymphocytic leukemia/ lymphoma 2, Bid = Bcl-2 interacting domain, C5-s = C5 sufficient, $\mathrm{C5}-\mathrm{d}=\mathrm{C}$ deficient, $\mathrm{CD}=$ cluster of differentiation, $\mathrm{CNS}=$ central nervous system, $\mathrm{CSF}=$ cerebrospinal fluid, $\mathrm{EAE}=$ experimental allergic encephalomyelitis, Fas $=$ cell death receptor 95/ apolipoprotein 1, IFN = interferon, IL = interleukin, MBP = myelin basic protein, MOG = myelin oligodendrocyte glycoprotein, mRNA = messenger ribonucleic acid, MS = multiple sclerosis, OLG = oligodendrocyte, PI3-K = phosphatidylinositol-3 kinase, Ser $=$ serine, $\mathrm{T}_{\mathrm{H}}=$ helper $\mathrm{T}$ cell, $\mathrm{TNF}=$ tumor necrosis factor, TUNEL = terminal deoxynucleotide transferase-mediated deoxyuridine triphosphate nick-end labeling.

* Address all correspondence to Horea Rus, MD, PhD; University of Maryland School of Medicine, Department of Neurology, 655 West Baltimore Street, BRB 12-014, Baltimore, MD 21201; 410-706-3170; fax: 410-706-0186.
}

Email: $\underline{\text { hrus@umaryland.edu }}$

DOI: 10.1682/JRRD.2004.08.0111 
lesions, but most axonal loss is seen in secondary progressive MS [2]. Based on careful analysis of MS lesions from biopsy and autopsy tissues, MS lesions have been classified by four distinct histopathologic patterns [3]. Pattern I lesions (12\% of cases) and Pattern II lesions (53\% of cases) are characterized by perivenous inflammation and large demyelinating plaques. Pattern II lesions also show deposition of immunoglobulins and activated complement proteins. Pattern III lesions (30\% of cases) are poorly demarcated and associated with relatively early loss of oligodendrocytes (OLGs) by apoptosis and loss of myelin-associated glycoprotein. Patients with Pattern III lesions appear to have a short remittingrelapsing clinical course. In Pattern IV lesions (4\% of cases), demyelination is perivenous and associated with cell necrosis [3]. Patients with Pattern IV lesions often show a primary progressive clinical course with cognitive dysfunction.

In the absence of $\mathrm{T}$ cells and activated macrophages, apoptotic OLGs were also found in new $(<3$ mo $)$ acute MS lesions [4]. The new lesions also showed deposition of the terminal complement complex C5b-9 on altered myelin [4]. These findings suggest that OLG apoptosis is affected not only by the type of MS lesion but also by the age and activity of the lesion. Therefore, a particular pattern may not represent a different type of lesion but rather the same lesion at a different stage of the disease. In this review, we will examine the pathophysiologies of MS and experimental allergic encephalomyelitis (EAE).

\section{MULTIPLE SCLEROSIS: AN INFLAMMATORY DISEASE}

EAE is a valuable animal model for investigating the inflammatory mechanisms of MS. Demyelination primarily results from a $\mathrm{T}$ cell-mediated immune response to various myelin antigens. EAE is induced by immunization with myelin, myelin proteins, and myelin protein encephalitogenic epitopes or by the passive transfer of myelin-reactive cluster of differentiation (CD) 4 cells. Myelin antigens or antigens that mimic myelin epitopes prime $\mathrm{T}$ and $\mathrm{B}$ cells in the peripheral lymphoid tissues [5-6]. T cell activation requires an initial signal from the presenting antigens together with costimulatory signals (e.g., binding of B7 protein on macrophages to CD28 receptor on $\mathrm{T}$ cells). $\mathrm{T}$ cells activated in this manner proliferate and differentiate into CD4, CD8, and cytotoxic $\mathrm{T}$ cells. CD4 $\mathrm{T}$ cells differentiate further into helper $\mathrm{T}$ cells $\left(\mathrm{T}_{\mathrm{H}}\right) 1$ and $2 . \mathrm{T}_{\mathrm{H}} 1$ cells synthesize inflammatory cytokines, such as tumor necrosis factor (TNF)- $\beta$, interferon (IFN) $\gamma$, and interleukin (IL)-2 [7]. $\mathrm{T}_{\mathrm{H}} 2$ cells produce the anti-inflammatory cytokines IL-4, IL-5, IL-10, IL-13, and transforming growth factor $\beta$. Studies have demonstrated the presence and activation of myelinreactive $\mathrm{T}$ cells in the blood and cerebrospinal fluid (CSF) of MS patients [8-9]. The $\mathrm{T}_{\mathrm{H}} 1$ cells of MS patients are biased toward myelin basic protein (MBP) and proteolipid protein reactive cells [10]. These data support the concept of MS as a $\mathrm{T}_{\mathrm{H}} 1$-driven autoimmune disease. MS is associated with the up-regulation of proinflammatory cytokines like TNF- $\alpha$, TNF- $\beta$, IFN- $\gamma$, and IL-12 [11]. Production of predominantly proinflammatory cytokines leads to up-regulation of endothelial cell adhesion molecules, to which $\mathrm{T}$ cells bind in a receptorspecific manner. These $T$ cells then enter the perivascular space via the blood-brain barrier (BBB); matrix metalloproteinases, which degrade the extracellular matrix of the BBB, facilitate this migration [12-13] (Figure 1).

Recent evidence suggests that chemokines are important mediators of T cell trafficking to the CNS [14]. Elevated expression of $\mathrm{C}-\mathrm{C}$ motif chemokine receptor (CCR) 2, CCR5, and CXC motif chemokine receptor 5 (CXCR5) on blood and CSF cells is associated with clinical relapse in some MS patients. These receptors and their ligands are also expressed on infiltrating lymphocytes in MS plaques. In the CNS, CD4 cells encounter antigens presented by microglia and astrocytes. Astrocytes and microglia can also regulate inflammation by releasing cytokines, chemokines, reactive oxygen species including nitric oxide (Figures 1-2).

Whether $\mathrm{T}$ cell subsets function as pro- or antiinflammatory effectors is not clearly defined [15-17]. Anti-inflammatory $\mathrm{T}_{\mathrm{H}} 2$ activity may also provoke demyelination, as seen in myelin oligodendrocyte glycoprotein (MOG)-induced EAE in Brown Norway rats. In this EAE model, expression of CCR3, a chemokine receptor associated with $\mathrm{T}_{\mathrm{H}} 2$ response, is frequently seen in infiltrating $\mathrm{T}$ cells [18]. More information is needed for a clear understanding of how $\mathrm{T}_{\mathrm{H}} 2$ cells affect the initiation of inflammation and how the inflammatory process per se may cause myelin loss. Cytotoxic MBP-specific CD8positive T cells and MOG-reactive T cells (in an adoptive transfer model) induced severe EAE manifestations [1920]. CD8-positive T cells are abundant in MS lesions and may be present in lesions, CSF, and blood for many years as the result of clonal expansion [21]. In aggressive disease 


\section{Central Nervous System}

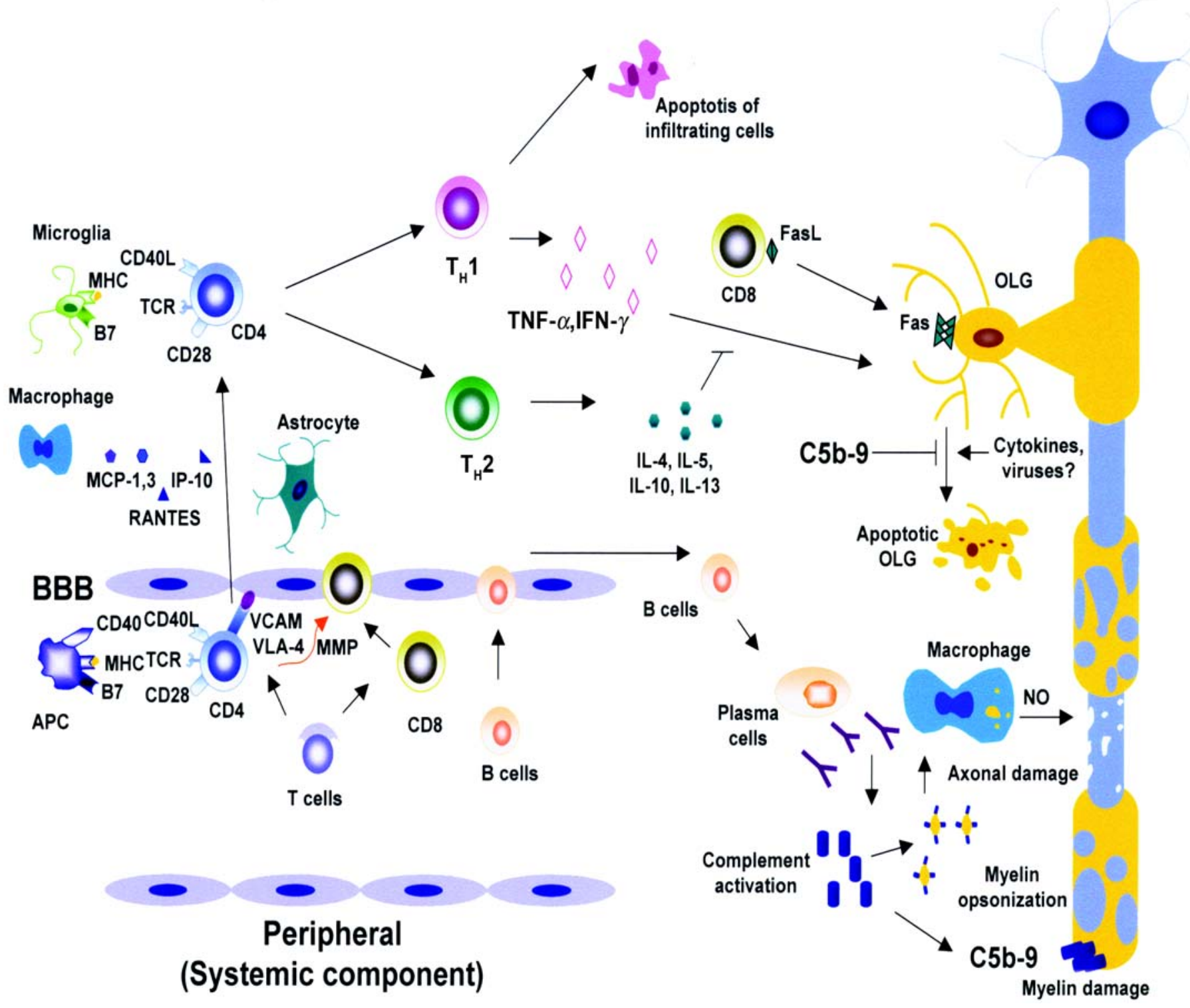

Figure 1.

Diagram of immune system role in multiple sclerosis pathogenesis. Immune response initiated in peripheral lymphoid tissue by myelin antigens or crossreactive foreign antigens presented by antigen-presenting cells (APC) to T cells. T cells require costimulatory signal, e.g., cluster of differentiation (CD) 28 receptor binding to B7 protein on macrophages. CD40 is expressed on APC and interacts with CD40L from CD4 T cells. T cell receptors (TCR) interact with major histocompatibility complex (MHC). Very late antigen (VLA-4) expressed on activated T cell surface interacts with vascular cell adhesion molecules (VCAM) and mediates endothelial cell adhesion. T cells are attracted by chemokines. Matrix metalloproteinases (MMP) help T cells cross the blood-brain barrier (BBB) into central nervous system, where T cells reencounter antigens presented by microglial cells through MHC class II molecules. Activated helper $\mathrm{T}$ cells $\left(\mathrm{T}_{\mathrm{H}}\right) 1$ produce proinflammatory, cytotoxic factors (tumor necrosis factor [TNF]- $\alpha$, interferon [IFN]- $\gamma$ ), which promote oligodendrocyte (OLG) death and demyelination. Macrophages and microglia play important roles in axonal damage. Demyelinated axons are vulnerable to degeneration by nitric oxide (NO). $\mathrm{T}_{\mathrm{H}} 2$ cells release anti-inflammatory cytokines (interleukin [IL]-4, IL-5, IL-10, IL-13) that inhibit $\mathrm{T}_{\mathrm{H}} 1$ cytokines. CD8-positive T cells directly affect OLGs by cell death receptor 95/apolipoprotein 1 (Fas) and Fas ligand (FasL) interaction, leading to OLG apoptosis and neuronal damage. B cells migrate into brain, encounter their specific antigen, then clonally expand and mature into plasma cells. Plasma cell antibodies induce demyelination by antibody-dependent, cell-mediated cytotoxicity and by complement system activation with C5b-9 assembly. Complement activation products are also important in myelin opsonization and uptake by macrophages through complement receptors. Sublytic C5b-9 may protect OLGs from apoptosis by inhibiting mitochondrial apoptotic pathway. Thus, complement activation plays a dual role in demyelination and OLG protection from apoptosis. IP-10 = interferon-inducible protein 10, MCP = monocyte chemotactic protein, RANTES = regulated on activation, normal T expressed and secreted. 


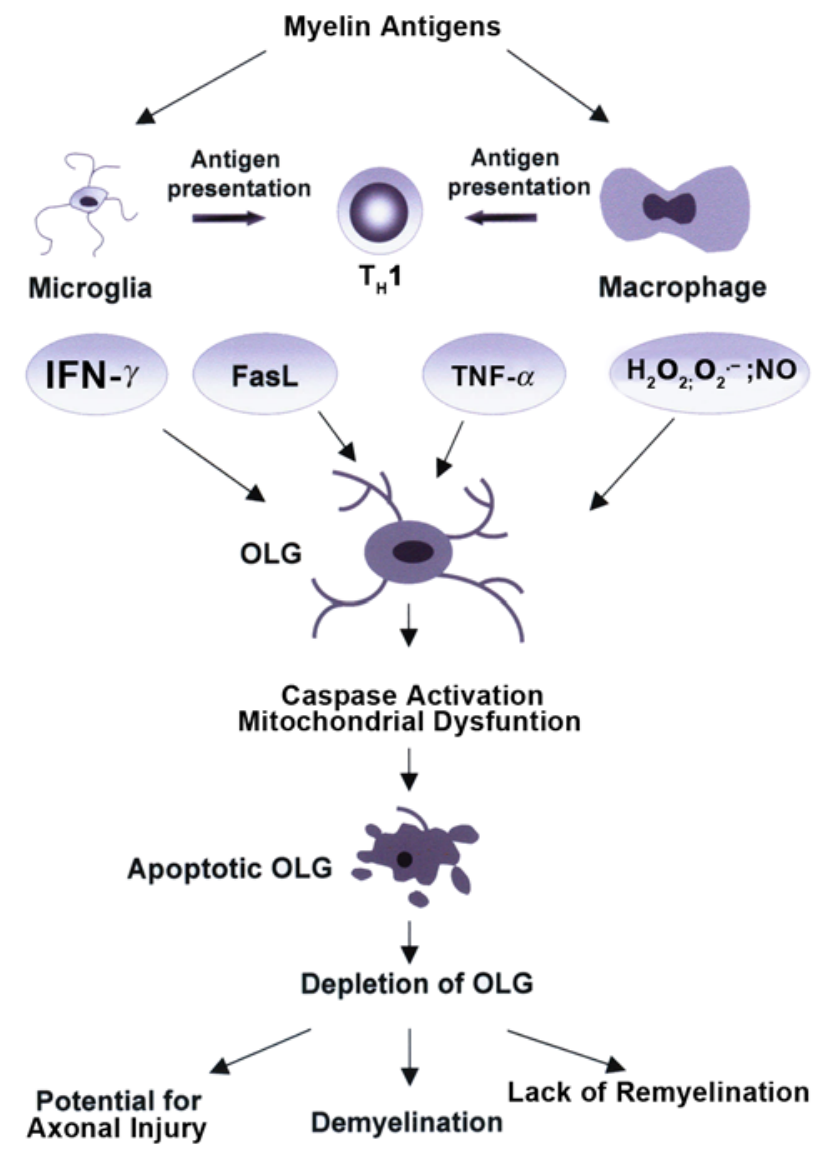

Figure 2.

Impact of cytokines on oligodendrocytes (OLGs) and demyelination in multiple sclerosis (MS). Myelin antigens initiate immune response. Activated microglia, helper $\mathrm{T}$ cells $\left(\mathrm{T}_{\mathrm{H}}\right) 1$, and macrophages in central nervous system produce cytokines and mediators (tumor necrosis factor [TNF]- $\alpha$, interferon [IFN]- $\gamma$, cell death receptor 95/ apolipoprotein 1 [Fas] ligand [FasL], and reactive oxygen species $\left.\left[\mathrm{H}_{2} \mathrm{O}_{2}, \mathrm{O}_{2}{ }^{-}, \mathrm{NO}\right]\right)$ that induce OLG activation and apoptosis. Proinflammatory cytokines induce caspase activation by interacting with specific receptor caspases and deregulate balance of pro- and antiapoptotic Bcl-2 (B cell chronic lymphocytic leukemia/lymphoma 2) protein family, leading to mitochondrial dysfunction and OLG apoptosis. Apoptosis contributes to OLG depletion in MS lesions and ultimately, increased demyelination. OLG depletion increases potential for axonal injury and lack of remyelination.

forms, these $\mathrm{T}$ cells are frequently localized close to OLGs and axons and express granzyme B [22].

Deposition of immunoglobulins and C5b-9 is seen in Devic's disease and Pattern II MS lesions [18]. C5b-9 is also found in most acute MS lesions less than 3 mo old [4]. Strong evidence indicates that the complement system is involved in demyelination through the assembly of terminal complement complex C5b-9 and that myelin is vulnerable to complement attack [23-24]. Hence, activation of the complement system may cause direct myelin damage. OLGs may withstand limited or sublytic complement attack by shedding membrane areas that contain C5b-9 complexes [25]. Thus, the effect of C5b-9 depends on the number of complexes inserted in the membrane. As detailed further in this review, assembly of sublytic C5b-9 can enhance OLG survival. Therefore, whether C5b-9 is detrimental or beneficial during inflammatory demyelination is defined by the level of complement activation and the phase of the disease process, especially the natural course of inflammation.

\section{MEDIATORS OF OLIGODENDROCYTE DEATH IN MULTIPLE SCLEROSIS}

\section{Fas-Fas Ligand System}

Cell death receptor 95/apolipoprotein 1 (Fas) is a member of the TNF receptor (TNFR) superfamily. Fas is expressed on the cell surface and is responsible for transducing cell death signals [26]. Binding of Fas ligand (FasL) to Fas results in caspase 8 activation, which in turn activates and cleaves B cell chronic lymphocytic leukemia/lymphoma 2 (Bcl-2) interacting domain (Bid), a member of the Bcl-2 family. Truncated Bid is then translocated to the mitochondrial membrane where it initiates apoptosis by releasing cytochrome c [27]. Immunohistochemical analysis revealed increased Fas expression on OLGs on MS lesions; furthermore, the microglia and lymphocytes in the lesions showed intense staining for FasL [28]. In addition, terminal deoxynucleotide transferase-mediated deoxyuridine triphosphate nick-end labeling (TUNEL)-positive cells are colocalized with FasL in MS lesions. These findings indicate that the Fas-FasL system is involved in apoptosis seen in MS [29]. Human OLGs are susceptible to FasL-induced apoptosis [28]. Treatment with IFN- $\gamma$ increases Fas expression on OLGs in vitro and thus enhances their susceptibility to FasLinduced apoptosis [28]. FasL can induce caspase activation and cell death in human OLG hybrid cells [30-31]. In addition, OLGs from mice that overexpress the p35 protein [32] or transgenic mice that are deficient in caspase 11 [33] show partial resistance to FasL-induced apoptosis. In vivo studies have also revealed the critical role of Fas-FasL interaction in apoptosis [34]. Enhanced expression of FasL on lymphocytes correlates with EAE development, whereas the expression of Fas on brain cells may play a role in EAE development. Interestingly, 
recovery from EAE may depend on the expression of FasL and apoptosis of infiltrating lymphocytes [35-36]. Intrathecal administration of FasL in mice with EAE also suppresses inflammation and disease activity [37] by enhancing the death of infiltrative lymphocytes. Together these data suggest that OLGs are susceptible to FasLmediated, caspase-induced apoptotic death and that FasL plays distinct roles during the initiation and recovery phases of EAE.

\section{Tumor Necrosis Factor $\alpha$}

TNF- $\alpha$ and IFN- $\gamma$ are important modulators of the $\mathrm{T}_{\mathrm{H}} 1$ immune response. TNF- $\alpha$ can induce both apoptotic and necrotic death of OLGs. Caspase 1 and caspase 3 inhibition protects OLGs against TNF- $\alpha$-induced apoptosis [38-41]. In normal adult rat brains, OLGs express TNFR2, a receptor involved in cell growth, but not TNFR1, which mediates cell death [42]. TNFR1 is expressed on OLGs, microglia, or astrocytes in culture [43-44] and may be important in demyelination in vivo. Microglia may mediate OLG death through TNF- $\alpha$ production [45]. The high levels of TNF- $\alpha$ found in the CSF of patients with chronic progressive MS are correlated with the severity and progression of the disease [46]. Since neutralization of TNF caused increased disease activity and TNF-neutralizing agents provoked inflammatory demyelination [47], TNF- $\alpha$ may act not only as a proinflammatory and demyelinating factor but may also protect the host from demyelination.

\section{Interferon $\gamma$}

IFN- $\gamma$ is produced by lymphocytes in MS lesions, and systemic administration of IFN- $\gamma$ exacerbates MS [48]. IFN- $\gamma$ can also be cytotoxic to OLGs in culture by modulating the cellular response to injury; these responses involve up-regulation of Fas expression [30,32-33] (Figure 2). Caspase 11 is an apical caspase that activates caspase 3 and 1 . OLGs from caspase 11 knock-out mice are less sensitive to IFN- $\gamma$-induced cell death, which also indicates that caspase is required for cell death. TNF- $\alpha$ increases the OLG-progenitor cell death induced by IFN- $\gamma$, which is partially suppressed by caspase inhibitors [49].

\section{ROLE OF OLG APOPTOSIS IN MULTIPLE SCLEROSIS AND EAE}

In MS, demyelination is accompanied by extensive destruction and loss of OLGs [50]. The failure of axons to remyelinate during the recovery phase of an acute attack is partly due to the death of injured OLGs and the failure of OLG progenitors to mature and remyelinate axons [51]. OLG loss in MS may occur by apoptosis and/or necrosis. In acute MS, 14 to 40 percent of OLGs die by apoptosis as measured by the TUNEL method [29]. This OLG apoptosis is rarely seen in chronic MS [52]. Because apoptotic cells are rapidly removed in vivo, apoptotic OLGs are difficult to demonstrate in old MS lesions. Barnett and Prineas proposed that OLG apoptosis is the initial event in new lesion formation and the primary cause of inflammation in MS [4]. By examining relapsingremitting MS lesions within $24 \mathrm{~h}$ of an acute attack, the authors concluded that OLG death incited a series of responses, such as activation of complement and microglia. These responses were then followed by the demyelination seen with macrophage phagocytosis of vesiculated and opsonized myelin sheets. These observations indicate that OLG death precedes inflammation and demyelination in MS.

Significantly elevated caspase 1 messenger ribonucleic acid (mRNA) was found in the brains of patients with acute and chronic MS [53]. The presence of this mRNA was correlated with increased immunostaining of caspase 1 in MS brains and OLGs. Caspase 1-deficient mice develop a less severe form of EAE [54]. These findings are consistent with data from transgenic mice in which antiapoptotic, caspase-inhibitory protein p35 is overexpressed [32]. These mice were less susceptible to EAE and had fewer apoptotic cells. In vitro, OLGs from these transgenic mice were also resistant to cytotoxicity induced by FasL, TNF- $\alpha$, or IFN- $\gamma$. The role of caspases in EAE was further supported by studies of mice that were deficient in the expression of caspase 11 [33]. The caspase 11 knock-out mice, compared with wild type, had significantly reduced incidence and severity of EAE and fewer OLGs that were positive for caspase 3 . These data clearly suggest an important role for caspases in OLG apoptosis in autoimmune demyelination.

\section{COMPLEMENT COMPLEX C5b-9}

\section{Sublytic Complement Attack Protects Oligodentrocytes from Apoptosis}

As assessed by the TUNEL method, more than 50 percent of OLGs differentiated in the absence of serum growth factor for $72 \mathrm{~h}$ in vitro are apoptotic. This differentiation-induced apoptosis of OLGs is inhibited by caspase 
3 inhibitors and exposure to sublytic amounts of C5b-9 [55-56]. Apoptosis is initiated in OLG concomitant with a rapid decline in phosphatidylinositol-3 kinase (PI3-K) activity and Bcl-2 mRNA expression, a gradual increase in caspase 3 mRNA, and the eventual release of cytochrome c and activation of caspase 9 [56]. A sublytic amount of C5b-9 inhibits these apoptotic activities. Thus, C5b-9 rescues OLGs from serum-deprivation-induced apoptosis by inhibiting the mitochondrial pathway of apoptosis. In addition, the ability of TNF- $\alpha$ to promote cell death and caspase 3 activation in OLGs and the ability of C5b-9 to counteract the effect of TNF- $\alpha$ suggest an additional role for C5b-9 in inhibition of the mitochondrial pathway of apoptosis [56].

Upstream signaling studies showed that C5b-9 induced strong PI3-K/Akt activities in OLGs; these activities in turn phosphorylated Bcl-2-associated death promoter (Bad). Binding of Bad to B cell lymphoma-X long (Bcl-XL) is thought to cause mitochondrial damage by displacing Bcl-XL and allowing oligomerization of proapoptotic Bcl-2-associated X (Bax) and Bcl-2-antagonist/ killer (Bak). On the other hand, dissociation of Bad from Bcl-XL and binding of Bad to cytoplasmic 14-3-3 proteins increase cell survival and require phosphorylation of Bad at serine (Ser) 112, Ser136, and possibly Ser156 [57]. C5b-9 increased Bad phosphorylation at Ser112 and Ser136 and caused Bad/Bcl-XL complex dissociation [58]. Both processes were reversed by pertussis toxin and the PI3-K inhibitor LY240092. Since Bad is phosphorylated by multiple kinases, kinases other than Akt, which phosphorylates Ser136, may have been activated. Therefore, sublytic C5b-9 attack appears to increase OLG survival, in part, by activating signaling pathways important in Bad phosphorylation and subsequent alteration of the association of Bcl-XL with Bad.

\section{Dual Role of C5b-9 In Vivo: Proinflammatory Demyelination and Oligodentrocyte Protection}

Complement involvement in demyelination in vivo has been studied in EAE by inhibiting complement activation or using rodents deficient in complement components. In rats, EAE was ameliorated by depletion or inhibition of complement with cobra venom factor or soluble complement receptor 1 [59-60]. Complement C3 and factor B knock-out mice developed less severe EAE than control mice, which indicates an enhancing role of the alternative pathway [61]. The importance of C5b-9 in demyelination and axonal damage was recently investigated in C6- deficient rats [62-63]. The C6-deficient rats showed significantly reduced disease activities and demyelination [62]. We analyzed the influence of C5 on inflammatory demyelination during EAE in C5-deficient (C5-d) mice for up to 120 days and found striking differences [64]. In C5-d mice, the severe inflammatory demyelination seen in acute EAE progressed to gliosis and was associated with axonal loss. On the other hand, C5-sufficient (C5-s) mice showed prominent myelin repair and axon preservation during the chronic phase of EAE. We also analyzed the effect of C5 on OLG apoptosis during EAE in C5-d mice [65]. In acute EAE, C5-d and C5-s mice had similar numbers of total apoptotic cells. During recovery, however, C5-s mice showed significantly fewer apoptotic cells than C5-d mice. In addition, although both mouse groups displayed TUNEL-positive OLGs, C5-s mice had significantly fewer TUNEL-positive OLGs than C5-d mice during both acute EAE and recovery phases [65]. These findings are consistent with the role of C5 in protecting OLG from apoptosis in EAE, possibly by forming C5b-9 and promoting remyelination during recovery.

Activated complement proteins, such as C3d and C5b-9, were associated with vacuolated myelin sheets and myelin engulfed by macrophages [3-4]. Deposition of C5b-9 has also been shown in Pattern II but not Pattern III lesions where apoptotic OLGs are prevalent [3]. Although OLG apoptosis may occur in all MS lesions, Pattern III lesions show significantly more apoptotic OLGs. One might speculate that apoptotic OLGs are seen less frequently in Pattern II because of the activation of complement and subsequent rescue of OLGs from apoptosis. This theory is contradicted by the recent finding that C3d and C5b-9 were also associated with apoptotic OLGs in acute lesions [4]. In their study, Barnett and Prineas suggest that OLG apoptosis is prephagocytic and represents an early stage in the formation of most lesions in relapsing-remitting MS. Complement activation might play a role in the clearance of vacuolated myelin by macrophages in MS (Figure 1). At the same time, the presence of C5b-9 suggests that complement activation may contribute to inflammation and demyelination in the acute phase of MS but reduce OLG apoptosis in the chronic phase of MS (Figure 1).

\section{CONCLUSION}

Taken together, recent data indicate that OLG apoptosis plays an important role in the pathogenesis of MS. 
Moreover complement system activation enhances OLG survival and therefore is protective.

\section{ACKNOWLEDGMENTS}

We thank Jennifer Macke for editing the manuscript. This material was based on work supported in part by the National Institute of Neurological Disorders and Stroke, grant R01 NS42011 (Dr. Rus), and the Department of Veterans Affairs Maryland Health Care System, MS Center of Excellence (Dr. Rus).

\section{REFERENCES}

1. Steinman L. Multiple sclerosis: a two-stage disease. Nat Immunol. 2001;2(9):762-64. [PMID: 11526378]

2. Compston A. The pathogenesis and basis for treatment in multiple sclerosis. Clin Neurol Neurosurg. 2004;106(3): 246-48. [PMID: 15177777]

3. Lucchinetti CF, Bruck W, Noseworthy J. Multiple sclerosis: recent developments in neuropathology, pathogenesis, magnetic resonance imaging studies and treatment. Curr Opin Neurol. 2001;14(3):259-69. [PMID: 11371747]

4. Barnett MH, Prineas JW. Relapsing and remitting multiple sclerosis: pathology of the newly forming lesion. Ann Neurol. 2004;55(4):458-68. [PMID: 15048884]

5. Hemmer B, Archelos JJ, Hartung HP. New concepts in the immunopathogenesis of multiple sclerosis. Nat Rev Neurosci. 2002;3(4):291-301. [PMID: 11967559]

6. Vanderlugt CL, Miller SD. Epitope spreading in immunemediated diseases: implications for immunotherapy. Nat Rev Immunol. 2002;2(2):85-95. [PMID: 11910899]

7. Ledeen RW, Chakraborty G. Cytokines, signal transduction, and inflammatory demyelination: review and hypothesis. Neurochem Res. 1998;23(3):277-89. PMID: 9482240]

8. Hellings N, Baree M, Verhoeven C, D’hooghe MB, Medaer R, Bernard CC, Raus J, Stinissen P. T-cell reactivity to multiple myelin antigens in multiple sclerosis patients and healthy controls. J Neurosci Res. 2001;63(3): 290-302. [PMID: 11170179]

9. Lovett-Racke AE, Trotter JL, Lauber J, Perrin PJ, June CH, Racke MK. Decreased dependence of myelin basic proteinreactive $T$ cells on CD28-mediated costimulation in multiple sclerosis patients. A marker of activated/memory T cells. J Clin Invest. 1998;101(4):725-30. [PMID: 9466965] Erratum in: J Clin Invest. 1998;101(7):1542.

10. Tejada-Simon MV, Hong J, Rivera VM, Zhang JZ. Reactivity pattern and cytokine profile of $\mathrm{T}$ cells primed by myelin peptides in multiple sclerosis and healthy individuals. Eur J Immunol. 2001;31(3):907-17. [PMID: 11241296]

11. Ozenci V, Kouwenhoven M, Link H. Cytokines in multiple sclerosis: methodological aspects and pathogenic implications. Mult Scler. 2002;8(5):396-404. [PMID: 12356206]

12. Sellebjerg F, Sorensen TL. Chemokines and matrix metalloproteinase-9 in leukocyte recruitment to the central nervous system. Brain Res Bull. 2003;61(3):347-55.

[PMID: 12909304]

13. Bar-Or A, Nuttall RK, Duddy M, Alter A, Kim HJ, Ifergan I, Pennington CJ, Bargoin P, Edwards DR, Yong VW. Analyses of all matrix metalloproteinase members in leukocytes emphasize monocytes as major inflammatory mediators in multiple sclerosis. Brain. 2003;126(Pt 12): 2738-49. [PMID: 14506071]

14. Babcock A, Owens T. Chemokines in experimental autoimmune encephalomyelitis and multiple sclerosis. Adv Exp Med Biol. 2003;520:120-32. [PMID: 12613576]

15. Lafaille JJ, Keere FV, Hsu AL, Baron JL, Haas W, Raine CS, Tonegawa S. Myelin basic protein-specific T helper 2 (Th2) cells cause experimental autoimmune encephalomyelitis in immunodeficient hosts rather than protect them from the disease. J Exp Med. 1997;186(2):307-12.

[PMID: 9221760]

16. Cannella B, Gao YL, Brosnan C, Raine CS. IL-10 fails to abrogate experimental autoimmune encephalomyelitis. J Neurosci Res. 1996;45(6):735-46. [PMID: 8892085]

17. Stefferl A, Brehm U, Storch M, Lambracht-Washington D, Bourquin C, Wonigeit K, Lassmann H, Linington C. Myelin oligodendrocyte glycoprotein induces experimental autoimmune encephalomyelitis in the "resistant" Brown Norway rat: disease susceptibility is determined by MHC and MHC-linked effects on the B cell response. J Immunol. 1999;163(1):40-49. [PMID: 10384097]

18. Lucchinetti CF, Mandler RN, McGavern D, Bruck W, Gleich G, Ransohoff RM, Trebst C, Weinshenker B, Wingerchuk D, Parisi JE, Lassmann H. A role for humoral mechanisms in the pathogenesis of Devic's neuromyelitis optica. Brain. 2002;125(Pt 7):1450-61. [PMID: 12076996]

19. Huseby ES, Liggitt D, Brabb T, Schnabel B, Ohlen C, Goverman J. A pathogenic role for myelin-specific CD8(+) $\mathrm{T}$ cells in a model for multiple sclerosis. J Exp Med. 2001;194(5):669-76. [PMID: 11535634]

20. Sun D, Whitaker JN, Huang Z, Liu D, Coleclough C, Wekerle H, Raine CS. Myelin antigen-specific CD8+ T cells are encephalitogenic and produce severe disease in C57BL/6 mice. J Immunol. 2001;166(12):7579-87.

[PMID: 11390514]

21. Skulina C, Schmidt S, Dornmair K, Babbe H, Roers A, Rajewsky K, Wekerle H, Hohlfeld R, Goebels N. Multiple sclerosis: Brain-infiltrating CD8+ T cells persist as clonal 
expansions in the cerebrospinal fluid and blood. Proc Natl Acad Sci U S A. 2004;101(8):2428-33. [PMID: 14983026]

22. Neumann H, Medana IM, Bauer J, Lassmann H. Cytotoxic T lymphocytes in autoimmune and degenerative CNS diseases. Trends Neurosci. 2002;25(6):313-19. [PMID: 12086750]

23. Seil FJ. Tissue culture studies of demyelinating disease: a critical review. Ann Neurol. 1977;2(4):345-55. [PMID: 617271]

24. Liu WT, Vanguri P, Shin ML. Studies on demyelination in vitro: the requirement of membrane attack components of the complement system. J Immunol. 1983;131(2):778-82. [PMID: 6863930]

25. Scolding NJ, Morgan BP, Houston WA, Linington C, Campbell AK, Compston DA. Vesicular removal by oligodendrocytes of membrane attack complexes formed by activated complement. Nature. 1989;339(6226):620-22. [PMID: 2733792]

26. Sharma K, Wang RX, Zhang LY, Yin DL, Luo XY, Solomon JC, Jiang RF, Markos K, Davidson W, Scott DW, Shi YF. Death the Fas way: regulation and pathophysiology of CD95 and its ligand. Pharmacol Ther. 2000;88(3):333-47. [PMID: 11337030]

27. Esposti MD. The roles of Bid. Apoptosis. 2002;7(5):433-40. [PMID: 12207176]

28. D’Souza SD, Bonetti B, Balasingam V, Cashman NR, Barker PA, Troutt AB, Raine CS, Antel JP. Multiple sclerosis: Fas signaling in oligodendrocyte cell death. J Exp Med. 1996;184(6):2361-70. [PMID: 8976190]

29. Dowling P, Husar W, Menonna J, Donnenfeld H, Cook S, Sidhu M. Cell death and birth in multiple sclerosis brain. J Neurol Sci. 1997;149(1):1-11. [PMID: 9168159]

30. Pouly S, Becher B, Blain M, Antel JP. Interferon-gamma modulates human oligodendrocyte susceptibility to Fasmediated apoptosis. J Neuropathol Exp Neurol. 2000;59(4): 280-86. [PMID: 10759183]

31. Li W, Maeda Y, Ming X, Cook S, Chapin J, Husar W, Dowling P. Apoptotic death following Fas activation in human oligodendrocyte hybrid cultures. J Neurosci Res. 2002;69(2):189-96. [PMID: 12111800]

32. Hisahara S, Araki T, Sugiyama F, Yagami K, Suzuki M, Abe K, Yamamura K, Miyazaki J, Momoi T, Saruta T, Bernard CC, Okano H, Miura M. Targeted expression of baculovirus p35 caspase inhibitor in oligodendrocytes protects mice against autoimmune-mediated demyelination. EMBO J. 2000;19(3):341-48. [PMID: 10654933]

33. Hisahara S, Yuan J, Momoi T, Okano H, Miura M. Caspase-11 mediates oligodendrocyte cell death and pathogenesis of autoimmune-mediated demyelination. J Exp Med. 2001;193(1):111-22. [PMID: 11136825]

34. Choi C, Benveniste EN. Fas ligand/Fas system in the brain: regulator of immune and apoptotic responses. Brain Res Brain Res Rev. 2004;44(1):65-81. [PMID: 14739003]
35. Sabelko-Downes KA, Cross AH, Russell JH. Dual role for Fas ligand in the initiation of and recovery from experimental allergic encephalomyelitis. J Exp Med. 1999;189(8): 1195-1205. [PMID: 10209037]

36. Sabelko-Downes KA, Russell JH, Cross AH. Role of FasFasL interactions in the pathogenesis and regulation of autoimmune demyelinating disease. J Neuroimmunol. 1999; 100(1-2):42-52. [PMID: 10695714]

37. Zhu B, Luo L, Chen Y, Paty DW, Cynader MS. Intrathecal Fas ligand infusion strengthens immunoprivilege of central nervous system and suppresses experimental autoimmune encephalomyelitis. J Immunol. 2002;169(3):1561-69.

[PMID: 12133985]

38. Robbins DS, Shirazi Y, Drysdale BE, Lieberman A, Shin HS, Shin ML. Production of cytotoxic factor for oligodendrocytes by stimulated astrocytes. J Immunol. 1987;139(8): 2593-97. [PMID: 3116087]

39. Selmaj KW, Raine CS. Tumor necrosis factor mediates myelin and oligodendrocyte damage in vitro. Ann Neurol. 1988;23(4):339-46. [PMID: 3132891]

40. Louis JC, Magal E, Takayama S, Varon S. CNTF protection of oligodendrocytes against natural and tumor necrosis factor-induced death. Science. 1993;259(5095):689-92. [PMID: 8430320]

41. Hisahara S, Shoji S, Okano H, Miura M. ICE/CED-3 family executes oligodendrocyte apoptosis by tumor necrosis factor. J Neurochem. 1997;69(1):10-20. [PMID: 9202289]

42. Tchelingerian JL, Monge M, Le Saux F, Zalc B, Jacque C. Differential oligodendroglial expression of the tumor necrosis factor receptors in vivo and in vitro. J Neurochem. 1995;65(5):2377-80. [PMID: 7595529]

43. Lieberman AP, Pitha PM, Shin HS, Shin ML. Production of tumor necrosis factor and other cytokines by astrocytes stimulated with lipopolysaccharide or a neurotropic virus. Proc Natl Acad Sci U S A. 1989;86(16):6348-52. [PMID: 2474832]

44. Chung IY, Benveniste EN. Tumor necrosis factor-alpha production by astrocytes. Induction by lipopolysaccharide, IFN-gamma, and IL-1 beta. J Immunol. 1990;144(8): 2999-3007. [PMID: 2109008]

45. Merrill JE, Ignarro LJ, Sherman MP, Melinek J, Lane TE. Microglial cell cytotoxicity of oligodendrocytes is mediated through nitric oxide. J Immunol. 1993;151(4):213241. [PMID: 8102159]

46. Sharief MK, Hentges R. Association between tumor necrosis factor-alpha and disease progression in patients with multiple sclerosis. N Engl J Med. 1991;325(7):467-72. [PMID: 1852181]

47. Mohan N, Edwards ET, Cupps TR, Oliverio PJ, Sandberg G, Crayton H, Richert JR, Siegal JN. Demyelination occurring during anti-tumor necrosis factor alpha therapy for 
inflammatory arthritides. Arthritis Rheum. 2001;44(12): 2862-69. [PMID: 11762947]

48. Panitch HS, Hirsch RL, Schindler J, Johnson KP. Treatment of multiple sclerosis with gamma interferon: exacerbations associated with activation of the immune system. Neurology. 1987;37(7):1097-1102. [PMID: 3110648]

49. Andrews T, Zhang P, Bhat NR. TNF potentiates IFNinduced cell death in oligodendrocyte progenitors. J Neurosci Res. 1998;54(5):574-83. [PMID: 9843148]

50. Ozawa K, Suchanek G, Breitschopf H, Bruck W, Budka H, Jellinger K, Lassmann H. Patterns of oligodendroglia pathology in multiple sclerosis. Brain. 1994;117(Pt 6): 1311-22. [PMID: 7820568]

51. Wolswijk G. Oligodendrocyte survival, loss and birth in lesions of chronic-stage multiple sclerosis. Brain. 2000; 123(Pt 1):105-15. [PMID: 10611125]

52. Bonetti B, Raine CS. Multiple sclerosis: oligodendrocytes display cell death-related molecules in situ but do not undergo apoptosis. Ann Neurol. 1997;42(1):74-84. [PMID: 9225688]

53. 53. Ming X, Li W, Maeda Y, Blumberg B, Raval S, Cook SD, Dowling PC. Caspase-1 expression in multiple sclerosis plaques and cultured glial cells. J Neurol Sci. 2002; 197(1-2):9-18. [PMID: 11997061]

54. Furlan R, Martino G, Galbiati F, Poliani PL, Smiroldo S, Bergami A, Desina G, Comi G, Flavell R, Su MS, Adorini L. Caspase-1 regulates the inflammatory process leading to autoimmune demyelination. J Immunol. 1999;163(5): 2403-9. [PMID: 10452974]

55. Rus H, Niculescu F, Shin ML. Sublytic complement attack induces cell cycle in oligodendrocytes. J Immunol. 1996; 156(12):4892-4900. [PMID: 8648139]

56. Soane L, Rus H, Niculescu F, Shin ML. Inhibition of oligodendrocyte apoptosis by sublytic C5b-9 is associated with enhanced synthesis of bcl-2 and mediated by inhibition of caspase-3 activation. J Immunol. 1999;163(11):6132-38. [PMID: 10570303$]$

57. Zha J, Harada H, Yang E, Jockel J, Korsmeyer SJ. Serine phosphorylation of death agonist BAD in response to survival factor results in binding to 14-3-3 not BCL-X(L). Cell. 1996;87(4):619-28. [PMID: 8929531]
58. Soane L, Cho HJ, Niculescu F, Rus H, Shin ML. C5b-9 terminal complement complex protects oligodendrocytes from death by regulating Bad through phosphatidylinositol 3-kinase/Akt pathway. J Immunol. 2001;167(4):2305-11. [PMID: 11490019]

59. Linington C, Morgan BP, Scolding NJ, Wilkins P, Piddlesden S, Compston DA. The role of complement in the pathogenesis of experimental allergic encephalomyelitis. Brain. 1989;112(Pt 4):895-911. [PMID: 2476195]

60. Piddlesden SJ, Storch MK, Hibbs M, Freeman AM, Lassmann H, Morgan BP. Soluble recombinant complement receptor 1 inhibits inflammation and demyelination in antibody-mediated demyelinating experimental allergic encephalomyelitis. J Immunol. 1994;152(11):5477-84. [PMID: 8189065]

61. Nataf S, Carroll SL, Wetsel RA, Szalai AJ, Barnum SR. Attenuation of experimental autoimmune demyelination in complement-deficient mice. J Immunol. 2000;165(10): 5867-73. [PMID: 11067947]

62. Mead RJ, Singhrao SK, Neal JW, Lassmann H, Morgan BP. The membrane attack complex of complement causes severe demyelination associated with acute axonal injury. J Immunol. 2002;168(1):458-65. [PMID: 11751993]

63. Tran GT, Hodgkinson SJ, Carter N, Killingsworth M, Spicer ST, Hall BM. Attenuation of experimental allergic encephalomyelitis in complement component 6-deficient rats is associated with reduced complement C9 deposition, P-selectin expression, and cellular infiltrate in spinal cords. J Immunol. 2002;168(9):4293-4300. [PMID: 11970970]

64. Weerth SH, Rus H, Shin ML, Raine CS. Complement C5 in experimental autoimmune encephalomyelitis (EAE) facilitates remyelination and prevents gliosis. Am J Pathol. 2003;163(3):1069-80. [PMID: 12937147]

65. Niculescu T, Weerth S, Niculescu F, Cudrici C, Rus V, Raine CS, Shin ML, Rus H. Effects of complement C5 on apoptosis in experimental autoimmune encephalomyelitis. J Immunol. 2004;172(9):5702-6. [PMID: 15100315]

Submitted for publication August 31, 2004. Accepted in revised form November 16, 2004. 